International Journal of

Advanced Science and Convergence

\title{
The Effect of Class times on the Academic Performance of Students in Mathematics
}

\author{
Hector Manaligod ${ }^{1}$, Veronica R. Gamboa ${ }^{2}$, Norman G. Lee ${ }^{3}$ and Lamberto Ongkingco, Jr. ${ }^{4}$ \\ ${ }^{1-4}$ School of Management and Information Technology, De La Salle - College of Saint Benilde, Manila, \\ Philippines
}

\begin{abstract}
Background/Objectives: This study examined if there a significant difference in math scores between the morning and afternoon class sections of first-year undergraduate game development students in mathematics. Methods/Statistical analysis: This experimental study had a population of an unpaired group composed of a morning and an afternoon class time. The i-Ready ${ }^{\circledR}$ Online Mathematics Assessment by Curriculum Associates was used to measure the math scores of each group proctored by the researchers and analyzed using Levine's test (t-test) and Mann-Whitney U test. Findings: The results of the study show that there is no significant difference in math scores between the morning and the afternoon class times. Improvements/Applications: For future studies, the researchers aim to determine the math scores of the morning and afternoon class times of the different year undergraduate levels.
\end{abstract}

\section{Index Terms}

Circadian rhythm, I-Ready mathematics assessment, Mathematics performance, Time-of-day effects

\footnotetext{
Corresponding author: H. Manligod

hector.manaligod@benilde.edu.ph

- Manuscript received August 3, 2021

- Revised August 31, 2021 ; Accepted September 20, 2021

- Date of publication September 30, 2021

(c) The Academic Society of Convergence Science Inc.

2619-8150 ๑ 2019 IJASC. Personal use is permitted, but republication/redistribution requires IJASC permission.
} 


\section{INTRODUCTION}

Undergraduate Information Technology (IT) courses such as Computer Science, Game Development, and Information Systems have programming subjects, where mathematical disciplines are applied and integrated. The common disciplines are the following: Algebra, Probability and Statistics, Trigonometry, Calculus, Linear Algebra, Discrete Mathematics, and Applied Mathematics (Baldwin, Walker, \& Henderson, 2013; Gamedesigning.Org, 2020). The primary math domains of these disciplines are numbers and operations, algebra and algebraic thinking, measurement and data, and geometry. In creating new algorithms, students need the analytical skills to independently apply mathematical techniques. A high-math level is required for students who conduct research in an area that need a deep ability to work with its mathematics (Baldwin, Walker, \& Henderson, 2013). High school graduate students may have different math scores when they enter the undergraduate level, hence, they can result in different programming skill levels as well. Given the level of importance of mathematics in IT courses, recognizing the time of day or class time when math classes or exams are delivered can provide better learning opportunities and productivity in academic tasks.

Since mathematics is a subject that requires analytical skills, both the student and the teacher need optimum focus, vigilance, and concentration to be productive. The time of day when math subjects are taught needs more investigation and study since teachers and students may have different circadian rhythms resulting in productivity and student achievement.

The circadian rhythm is determined from the time a person goes to bed until the time he wakes up. From the time a person usually wakes up, a person's peak, trough, and rebound points during the day are recognized to be able to properly function with focus and vigilance (Pink, 2018). Students who have sleep regularity or have a more consistent circadian rhythm is positively correlated with academic performance (Phillips, et al., 2017; Raley, Naber, Cross, \& Perlow, 2016). Not everyone has the same sleeping patterns. Most adults and children are third birds (people who typically fall asleep around 11:30 pm and wakes up around 7:30 am), which is the profile of most teachers and elementary students. Adolescents and young adults, which is the profile of the high school and undergraduate students, are mostly owls (people who typically fall asleep around 2:00 am and wakes around 9:00 am) due to their biological changes and they also prefer to have late sleeping and waking times (Hines, 2004; Pink, 2018). Adolescents are struggling to an early bedtime because of the release of the hormone melatonin. The adolescent hormone explanation predicts that the effect of later start times will be larger for older students (Edwards, 2012; Phillips, et al., 2017). Many undergraduate students are still dealing with a biologically driven delayed sleep phase similar to adolescents (Alfonsi, Scarpelli, D'Atri, Stella, \& De Gennaro, 2020; Takhar, 2017). Therefore, adults and adolescents do not have synced time-of-day effects.

Undergraduate students have owl-like sleeping patterns, sleep deficiency, and, for some, insomnia, which greatly affect their academic performance and daily life (Alfonsi, Scarpelli, D'Atri, Stella, \& De Gennaro, 2020; Edwards, 2012; Schlarb, Friedrich, \& Claßen, 2017; Takhar, 2017). Because of these sleep deficiencies, when the students are at school, they are drowsy, fall asleep in class, and are not prepared and alert for school resulting in lower academic achievement (Takhar, 2017). Light exposure such as room light shifts can change sleeping schedules tremendously in humans. Individuals who frequently change their sleep schedules and the pattern of light/dark exposure may experience misalignment between the circadian rhythm and the sleep/wake cycle, which may have an adverse effect on both cognitive function and health (Gomes, Tavares, \& Azevedo, 2002; Phillips, et al., 2017). Furthermore, undergraduate students are sleepier than adults or teenagers and report more problems with memory and concentration (Gomes, Tavares, \& Azevedo, 2002; Hershner MD, 2015; Raley, Naber, Cross, \& Perlow, 2016; Takhar, 2017; Zerbini \& Merrow, 2017). Late chronotypes suffer in conscientiousness and motivation related to learning and school performance (Zerbini \& Merrow, 2017). Since undergraduate students and adolescents have similar sleeping patterns, the time-of-day effects on academic performance are the same.

Several studies on the time-of-day effects in math student achievement varied in terms of age group and educational attainment. According to SjostenBell (2005), elementary students have higher average math scores in the morning, followed by the midmorning, then the afternoon. The academic performance of pre-adolescent and early adolescents in terms of speed and accuracy were found to be significantly higher in the morning than in the afternoon (Hines, 2004). High school students have higher GPA scores in the morning than in the afternoon, especially in mathematics. High school students with morning math classes got higher grades on standardized tests than those who learned math in the last two periods of the day (Dimitrova, 2017; 
Learning Liftoff , 2017; Pink, 2018). The time-ofday effect may be concluded as differential productivity due to the circadian rhythm; "stamina effects, with decreasing productivity the longer a student is at school; or school structure effects such as lower productivity after a lunch break" (Pope, 2016). For adolescents, a one-hour delay in class start time in the morning shows increases in standardized test scores on both math and reading tests (Alfonsi, Scarpelli, D'Atri, Stella, \& De Gennaro, 2020; Edwards, 2012). Later start times increase students' achievement because students are less sleep-deprived (Pope, 2016). Furthermore, students who have later class start times have fewer absences, watch less television, and spend more time on academic work each week (Edwards, 2012).

In contrast, undergraduate students have lower GPAs in the morning and higher in the afternoon (Dills \& Hernandez-Julian, 2008; Luong, 2017). First-year undergraduate students who are assigned to early morning courses have lower GPAs than in a later time of day. More specifically, the grades of the students get significantly lower the earlier the class starts, where for certain courses taken at 8:15 a.m. perform better than at 6:30 a.m. and 7:20 a.m. This result is similar to circadian rhythm studies that these morning class times create adverse effects on academic performance (Luong, 2017).

Since mathematics is an important discipline in IT courses and the hypotheses of this study need to be tested, there is a need to investigate the effect of classtimes in math scores of first-year undergraduate game development students so that students and school administrators can rearrange class schedules based on their circadian rhythm, develop training programs, and select time preferences resulting in higher academic achievement. Schedule rearrangements do not have significant cost implications for the institution. Rearranging when academic tasks are done may have constraints due to school administrative concerns such as class schedules, teacher availability, and standard office hours (Pink, 2018). Some educational institutions dictate the schedule of an entire batch of students or more commonly known as a block section. Furthermore, school administrators can use this study as a basis to develop programs that will help students better manage their circadian rhythm and create awareness of the negative effects of sleep deprivation (Schlarb, Friedrich, \& Claßen, 2017).

This study aims to test if an unpaired group of first-year undergraduate game development students will get higher math scores in the morning than in the afternoon and if there is a relationship between math scores and class times. The researcher formulates the following hypotheses:

H1: There is no significant difference in math scores between the morning and afternoon class times of first-year undergraduate game development students.

$\mathrm{H} 2$ : There is no significant relationship between math scores class times of first-year undergraduate game development students.

Several research experiments have been conducted on time-of-day effects and have concluded that it does affect student achievement and performance. The age of each group is an important factor in this study since adolescents and first-year undergraduate students have the same sleeping patterns due to their biological changes. Gender was not considered a factor in this study because the majority of the population were male students. The i-Ready ${ }^{\circledR}$ Online Mathematics Assessment by Curriculum Associates was used to measure the math scores of the unpaired group in this study. Furthermore, the researchers tested the hypothesis and concluded that there is no significant difference in math scores between the morning and the afternoon class times. Therefore, the math score is not dependent on class time.

Generally, research studies on the experimentation of time-of-day effects often used class times or timeof-day and academic achievement e.g., standardized test scores, general point average (GPA), and an IQ test. Specific to mathematics, standardized math scores were widely accepted measures for quantitative studies because it is the basis for student achievement. The experiments were mostly longitudinal research that had rearrangements of class schedules with a combination of different subjects such as Mathematics, English, and History. The cohorts for most research studies were mostly elementary, high school, and undergraduate students in private and public schools, where age is a factor. In other studies, factors such as genetics, gender, and personality were also considered. The class start time varied per study, where the morning start time ranged between 8:00 am to 9:00 am and in the afternoon between 1:00 pm to 3:30 pm. Furthermore, most researchers conducted a combination of a paired and unpaired group of students using the test of significance, correlation, and multiple regression as statistical tools.

\section{METHODOLOGY}

\section{A. Methods and Materials}

An experimental design study was used to perform this research, where the class times were divided into two (2) different sections: morning (from 0940 to 1110) and afternoon (from 1440 to 1610) composed 
of the total population of the first year full-time undergraduate game development students in a college in Manila, where the majority of the students are male in gender. The morning class was a total of thirty-eight (38) students, while the afternoon class was a total of thirty-one (31) students.

This experimental study was conducted with the full consent of the students and school program administrators, where the full names of the students remained anonymous. This is also in compliance with the Data Privacy Act.

The i-Ready® Online Mathematics Assessment by Curriculum Associates was the instrument used to measure the math scores of students. This assessment is an adaptive, valid, and reliable instrument to determine the math scores of students based on the primary math domains: numbers and operations, algebra and algebraic thinking, measurement and data, and geometry. (Curriculum Associates, 2019). Since this assessment is also an adaptive diagnostic, the level of mastery in mathematics can also be measured using this instrument, which shows the current grade level of the student in math. The setting of the online math assessment for this study was set to Grade 12 since this was the math level expected of first-year undergraduate students. The test questions were random, stored in a test bank, and since the instrument is adaptive, the questions varied depending on the responses of the student.

The online math assessment was conducted in a computer laboratory in a private undergraduate school in Manila, and each student was assigned a computer unit. The environment of the computer laboratory was conducive for conducting the assessment since there was silence, sufficient lighting, and the air-conditioning was set at a cool temperature. All search engine websites and other applications in all the computer units were blocked and mobile phones were kept together with the personal belongings of the students. Furthermore, the students were proctored by the researchers to ensure the integrity of the assessment.

\section{B. Procedure}

Before the i-Ready ${ }^{\circledR}$ Online Mathematics Assessment, the researchers assigned anonymously a username and password for each student. This online assessment was conducted in one day last 3 April 2019. One class section in the morning (from 0940 to 1110) and in the afternoon (from 1440 to 1610). To administer the i-Ready® Online Mathematics Assessment, each student was tasked to do the following: 1) Enter assigned username and password; 2) Click on the Start Diagnostic button; 3) View instructions; 4) Answer/solve math questions. The students used pen and paper to compute and solve the mathematical calculations.

After the online math assessment, the researchers used the teacher's access in i-Ready® and generated the reports with the math scores of students who took the assessment in the morning and afternoon class times. The variables in this study were the following: math score was the independent variable, and the class time was the dependent variable. Using these two (2) variables, the researchers tested the hypothesis using Statistical Package for the Social Sciences (SPSS) and analyzed the data using T-Test for Independent samples that include was set to the Homogeneity of Variance test (Levene's Test for Equality of Variances). The t-Test for Independent Samples was used because the hypothesis test was to determine the difference between two (2) means (math scores of the morning and afternoon class times). Linear regression and coefficient of determination were used to determine the relationship between math scores and class time.

The researchers ensured the reliability of the data and conducted a Bootstrapping resampling simulation. A non-parametric test was also conducted using the Mann-Whitney $U$ test to validate if the results in the One-Way ANOVA were the same. Therefore, the Bootstrapping simulation and the Mann-Whitney $U$ test were conducted because there was a need to ensure that the data and results are consistent.

\section{RESULTS}

\section{A. Descriptive Statistics}

Using the i-Ready® Online Mathematics Assessment, the researchers generated a report containing the math scores of each student for the morning and afternoon class times. The researchers aim to determine if there is a significant difference in math scores between the morning and afternoon class sections and conclude whether students perform better in math in the morning than in the afternoon. Below are the results and conclusions of this study:

Table 1. DesCriptive STATISTICS

\begin{tabular}{lccc} 
Time of Day & $N$ & $M$ & $S D$ \\
\hline Morning & 38 & 530 & 16 \\
Afternoon & 31 & 524 & 23 \\
\hline
\end{tabular}

Table 1 shows the mean, standard deviation, and standard error mean of the morning and afternoon class times. The morning class section has a slightly higher mean as compared to the afternoon class section. The standard deviation of the morning class time is lower as compared to the afternoon class time. Since the study was an unpaired group of students, the total population of the first-year undergraduate 
game development students were not equal.

\section{B. H1: There is no significant difference in math scores between the morning and afternoon class times of first-year undergraduate game development students.}

Based on Levene's test, the variances are not equal, hence, the t-test for Equal Variance Not Assumed is selected $(p=.041)$. The t-test statistics showed that there is no significant difference between the morning and afternoon classes $(p=.273)$.

The results based on the bootstrapping method are the same. Based on the test of significance, the $p$ value is .041 and therefore equal variance was not assumed. Similar to the result of the previous test without bootstrapping, there is no significant difference in the Math scores between the morning and afternoon groups, $t=1.109, p=.273$, respectively.

The results of the Mann-Whitney $U$ test of the morning and afternoon class times have no significant difference between the two class sessions as shown by the probability value of .331. Therefore, the study failed to reject the null hypothesis.

\section{H2: There is no significant relationship between math scores and class times of first-year undergraduate game development students.}

There is a weak and non-significant correlation between math scores and class time ( $r$ $=.139, p=.255)$. The statistical result suggests that the extent of linear relationship between the two factors cannot be established with enough statistical evidence $(p>.05)$

\section{Conclusion}

Since the $\mathrm{p}$-value $(p=.041)$ of the Levene's Test for Homogeneity of Variance Equality of Variances is less than .05 , it is an assumption that the variances are equal was not accepted. Using the t-test of independent samples and bootstrapping techniques, there is enough evidence to conclude that there is no significant difference in the math scores between the morning and afternoon class times of the first-year undergraduate game development students. This is also validated with the result of the Mann-Whitney non-parametric statistical technique.

With respect to analysis on correlation, the result yielded a non-significant and weak relationship ( $r$ $=.139, p=.255$ ) between Math Score and Class Time. Although the afternoon class of 5.43 is lower compared to the morning this is not found to be significant. Causality was not established between Math score and class time session. The result of this study is similar to Sjoesten-Bell (2005), which also shows that there is no significant difference in math scores between the morning, mid-morning, and afternoon class times. Using an IQ test as a measure, Hines (2014) interprets that there is no significant difference between morning and afternoon testing times. On the other hand, studies conducted by Dimitrova (2017) and Pope (2016) show that students have higher math scores in the morning than in the afternoon.

The class start time may also be a differentiating factor because, in the studies of Dimitrova (2017) and Edwards (2012), morning class start time was between 7:15 am to 8:00 am, while the class start time of this study and Sjoesten-Bell (2005) was between 9:30 to 9:40 am. Edwards (2012) suggests that a delay in the class start time in the morning increases math scores. Hence, the class start time of this study and Sjoesten-Bell (2005) was later as compared to the studies of Dimitrova (2017) and Edwards (2012)

The age range and level of education of this study and Sjoesten-Bell (2005) had a disparity, in this case, elementary and undergraduate level. This concludes that even with empirical studies, the time-of-day effects vary, and this phenomenon remains to be unclear.

Dills and Hernandez-Julian (2008) and Luong (2017) conducted a time-of-day study on undergraduate students which suggests that grades are lower in the morning and higher in the afternoon. The measure of academic performance was the grade average of the entire semester and regardless of the combination of subjects. According to Dills and Hernandez-Julian (2008), there is a significant difference in academic performance in the morning and in the afternoon, which also shows the opposite result based on this study. Moreover, undergraduate students are sleepier than adults, which greatly affects the GPA of the students (Gomes, Tavares, \& Azevedo, 2002; Hershner MD, 2015; Pink, 2018; Raley, Naber, Cross, \& Perlow, 2016; Takhar, 2017; Zerbini \& Merrow, 2017). Therefore, afternoon class times for undergraduate students can provide better academic performance. Even though the result of this study suggests that there is no significant difference in math scores of the morning and afternoon class times and undergraduate students generally have sleep deficiencies, an afternoon class time for taking mathematics can provide a more consistent sleeping pattern for students in the morning resulting in better academic performance (Phillips, et al., 2017).

The correlation coefficient shows a very weak positive correlation between math scores and class times. Therefore, there was not enough evidence to 
establish that Math Score is affected by the type of class time, $r=.139, p=.255$, respectively. This result is similar to the study of Dills and Hernandez-Julian (2008), which also has a positive correlation with minimal significance. (Dills \& Hernandez-Julian, 2008)

Even after conducting the Bootstrap sampling simulation, the results of the Levene's Test for Equality of Variances of the current statistical data and the Bootstrapped results are the same. The $p$ value is still at .041 , which is less than .05 , therefore, there is no significant difference in the math scores between the morning and afternoon class times of first-year undergraduate game development students for the current and Bootstrapped data. The analyses and the conclusions are the same as the results of the One-Way ANOVA without the Bootstrap sampling simulation.

Since the $\mathrm{p}$-value $(p=.331)$ of the Mann-Whitney $\mathrm{U}$ Test is greater than .05, there is sufficient statistical evidence to retain the null hypothesis. Therefore, there is no significant difference in the math scores between the morning and afternoon class times of first-year undergraduate game development students. The analyses and the conclusions are the same as the results of the One-Way ANOVA with and without the Bootstrap sampling simulation.

Since the researchers were able to use a reliable instrument, which is the $\mathrm{i}$-Ready ${ }^{\circledR}$ Online Mathematics Assessment and were able to ensure the integrity of the assessment, the validity of the results of this study is reliable. The main assumption of this study is that math class times were conducted offline and consistent in terms of start and end times. Since the method of teaching can be conducted online, where a combination of asynchronous and synchronous methods can be performed, an online method of delivery may provide better flexibility for undergraduate students, especially for students who have irregular sleeping patterns.

For future studies, the researchers aim to determine the sleeping patterns of students to determine their circadian rhythm using the Pittsburgh Sleep Quality Index (PSQI) and its effect on math scores. Since mathematics requires analytical skills and are critical to the academic success of undergraduate students taking IT courses, an understanding of the circadian rhythm of the students can provide school administrators information on how to develop training programs that can help students manage their circadian rhythms (Schlarb, Friedrich, \& Claßen, 2017).

Furthermore, if the researchers would repeat this experimental study, the researchers aim to determine the math scores of the morning and afternoon class times of the higher year undergraduate level because theoretically, the math scores of the higher undergraduate levels should be higher as compared to the lower levels and the effects of the morning and afternoon class time may vary.

Since mathematics is a core discipline in IT courses and requires analytical skills, school administrators and teachers need to give more importance to class times because the sleeping patterns of undergraduate students and adults are different, which results in different time-of-day effects. Even though the results of this study show that there is no significant difference in math scores of the morning and afternoon class times and that math score is not dependent on class time, the results of this experiment vary and remain to be unclear. Hence, time-of-day experimental studies in taking mathematics should be conducted by all educational institutions to better understand the peak, trough, and rebound points of students and teachers. Class time scheduling for undergraduate students needs more flexibility and consideration so that the students may have more sleep. Moreover, the significance of sleep in the education industry and time-of-day effects should be given importance because of learning, mental health, quality of life, and safety of the students. Students should not be the only focus but adults as well, because adults also sacrifice sleep to meet their responsibilities (Hershner MD, 2015).

\section{ACKNOWLEDGMENT}

We would like to thank God for the provision, grace and guidance. To the Benildean community for all their support, especially Mr. Henry Jake DV. Castro and Atty. John Evan Miguel.

\section{REFERENCES:}

[1] Alfonsi, V., Scarpelli, S., D’Atri, A., Stella, G., \& De Gennaro, L. (2020). Later school start time: The impact of sleep on academic performance and health in the adolescent population. International Journal of Environmental Research and Public Health, 1-16. DOI: 10.3390/ijerph17072574

[2] Baldwin, D., Walker, H. M., \& Henderson, P. B. (2013, December). The Roles of Mathematics in Computer Science. Inroads, 4(4), 74-80. DOI: 10.1145/2537753.2537777

[3] Curriculum Associates. (2019, November). i-Ready Diagnostic and Growth Monitoring Received High Ratings from the National Center on Intensive Intervention. Retrieved from i-Ready NCII Review Overview 2019: https://www.curriculumassociates.com/-/media/mainsite/ files/i-ready/iready-ncii-review-overview-2019.pdf

[4] Dills, A. K., \& Hernandez-Julian, R. (2008). Course Scheduling and Academic Performance. Economics of Education Review, 27(6), 646-654. DOI: 10.2139/ssrn.756847

[5] Dimitrova, V. (2017). The afternoon effect: Differential impacts on student performance in maths and history. Economics of Education Association, 1-42. 
[6] Edwards, F. (2012). Early to rise? The effect of daily start times on academic performance. Baylor University Department of Economics, 1-12. DOI: 10.2139/ssrn.1628693

[7] Gamedesigning.Org. (2020, December 2). Intro to Math in Game Development and Programming | Gamedesigning.Org. Retrieved from https://www.gamedesigning.org/learn/gamedevelopment-math/

[8] Gomes, A. A., Tavares, J., \& Azevedo, M. H. (2002). Sleep-wake patterns and academic performance in university students. European Conference on Educational Research, 11-14.

[9] Hershner MD, S. (2015). Is sleep a luxury that college students cannot afford? Journal of the National Sleep Foundation, 13-14. DOI: 10.1016/j.sleh.2014.12.006

[10] Hines, C. B. (2004). Time-of-Day effects on human performance. The Journal of Catholic Education, 7(3), 390413. Retrieved from http://dx.DOI.org/10.15365/

[11] Learning Liftoff . (2017, January 17). How Class Schedules Impact Student Success | Learning Liftoff. Retrieved from https://www.learningliftoff.com/how-class-schedulesimpact-student-success/

[12] Luong, P. T. (2017, March). Time-of-Day effect on academic achievement of adolescents. Retrieved from Univesity of California Davis: http://giovanniperi.ucdavis.edu/uploads/ 5/6/8/2/56826033/phuc_luong_honor_thesis.pdf

[13] Phillips, A. J., Clerx, W. M., O’Brien, C. S., Sano, A., Barger, L. K., Picard, R. W., . . Czeisler, C. A. (2017, June 12). Irregular sleep/wake patterns are associated with poorer academic performance and delayed circadian and sleep/wake timing. Scientific Reports, 7(3216), 1-13. DOI: 10.1038/s41598-017-03171-4

[14] Pink, D. H. (2018). When: The scientific secrets of perfect timing. Riverhead Books.

[15] Pope, N. G. (2016). How the time of the day affects productivity: Evidence from school schedules. The Review of Economics and Statistics, 98(1), 1-11. DOI: 10.1162/REST_a_00525

[16] Raley, H., Naber, J., Cross, S., \& Perlow, M. (2016). The Impact of Duration of Sleep on Academic Performance in University Students. Madridge Journal of Nursing, 1(1), 1118. DOI: $10.18689 / \mathrm{mjn}-1000103$

[17] Schlarb, A. A., Friedrich, A., \& Claßen, M. (2017). Sleep problems in university students - an intervention । ncbi.nlm.nih.gov. Retrieved from US National Library of Medicine National Institutes of Health: https://www.ncbi.nlm.nih.gov/pmc/articles/PMC5536318/

[18] Sjosten-Bell, W. (2005, December). Influence of Time-ofDay on on student performance on mathematical algorithms. Retrieved from ERIC: Institute of Education Sciences: https://files.eric.ed.gov/fulltext/ED490712.pdf

[19] Takhar, M. K. (2017). Importance of Circadian Clocks: How the circadian clock affects a student's sleep schedule. UC Merced Undergraduate Research Journal, 10(1), 1-10. DOI : 10.5070/M4101037220

[20] Zerbini, G., \& Merrow, M. (2017). Time to learn: How chronotype impacts education. PsyCh Journal, 6, 263-276. DOI: $10.1002 /$ pchj. 178 